\title{
Programa de controle da doença de Chagas no Estado de São Paulo: aspectos soroepidemiológicos em microrregiões geográficas homogêneas
}

\author{
Chagas disease Control Program in the State of São Paulo, Brazil \\ Seroepidemiological aspects of homogeneous geographic microregions
}

\author{
Maria Esther de Carvalho*, Rubens Antonio da Silva*,**, Dalva Marli Valério Wanderley** \\ e José Maria Soares Barata***
}

\begin{abstract}
RESUMO
A infecção chagásica foi averiguada entre moradores de duas microrregiões geográficas homogêneas do Estado de São Paulo, entre os anos de 1976 a 1980. Campos de Itapetininga, na região de Sorocaba e Encosta Ocidental da Mantiqueira Paulista, na região de Campinas, foram áreas de colonização de Triatoma infestans, no passado, tendo permanecido, na primeira, até o início da década de 70, como reduto da espécie no estado. Atualmente as duas áreas são colonizadas por triatomíneos da espécie Panstrongylus megistus. Perfis de títulos sorológicos caracterizaram ambas as microrregiões como áreas de baixa endemicidade; a interrupção da transmissão foi mais precoce na Encosta, com diferença de 17 anos, em média. Em Campos de Itapetininga, a intensa exposição ao vetor é traduzida pela sororreatividade observada nas idades superiores a 20 anos, correspondentes aos nascidos antes de 1956. Dentre os nascidos entre 1972 e 1977, nessa área, permanece uma baixa positividade, podendo, também, associar-se à transmissão congênita. Na Encosta, a média de idade dos sororreagentes corresponde a nascimentos na década de 1930; os níveis de positividade variaram nos municípios que a compõe segundo o desenvolvimento de capital. Após 1984, com a adoção de novos critérios para o uso da sorologia no Programa de Controle, o encontro de sororreagente não tem sido associado estatisticamente a moradores notificantes de domicílios com presença de triatomíneos.
\end{abstract}

Palavras-chaves: Doença de Chagas. Diagnóstico sorológico. Inquérito populacional. Triatomíneos.

\begin{abstract}
Between the years 1976 and 1980, the American trypanosomiasis was searched for among residents in two geographic microregions of the State of São Paulo: Campos de Itapetininga, in the region of Sorocaba, and Encosta Ocidental da Mantiqueira Paulista, in the region of Campinas. Both areas have in the past been colonized by Triatoma infestans. Campos de Itapetininga remained, until the beginning of the 1970s as a stronghold of this species in the State of São Paulo. Panstrongylus megistus has currently colonized in these areas, now classified as having serological titer profiles characteristic of low endemicity. Transmission of Chagas disease was interrupted earlier in the Encosta Ocidental. Intense exposure to the vector in Campos de Itapetininga can explain the seroreactivity frequencies observed in people born before 1956, aged more than 20 years. Among the residents in this region born between 1972 and 1977, a low positivity rate remains, which might also include cases of congenital transmission. The mean age of seroreagents resident in the Encosta indicates that they must have been born in the 1930s; positivity levels here vary in different municipalities according to their growth in capital goods. After 1984 new criteria were adopted for the use of serology in the Program for the Control of Chagas disease, the detection of seroreagents has not been statistically associated to notification of the occurrence of domestic triatomines in these regions.
\end{abstract}

Key-words: Chagas disease. Serological diagnosis. Populational survey. Triatomines.

\section{INTRODUÇÃo}

Dentre as mais importantes avaliações sorológicas realizadas sobre a infecção chagásica no Estado de São Paulo, após a obtenção do controle do principal vetor responsável pela transmissão, Triatoma infestans (Klug, 1834), no final da década de 60 e início da de 70, destacam-se as de duas microrregiões geográficas homogêneas ${ }^{1}$. São elas, Campos de Itapetininga, na região de Sorocaba (Depressão Periférica) e Encosta Ocidental da Mantiqueira Paulista, na região de Campinas. Desenvolvidas

\footnotetext{
*Laboratório de Imunoepidemiologia, Superintendência de Controle de Endemias, Secretaria de Estado da Saúde. São Paulo, SP. ${ }^{* *}$ Diretoria de Combate a Vetores. Superintendência de Controle de Endemias, Secretaria de Estado da Saúde. São Paulo, SP. *** Departamento de Epidemiologia, Faculdade de Saúde Pública, Universidade de São Paulo. São Paulo, SP.

Endereço para correspondência: Dr ${ }^{\mathrm{a}}$ Maria Esther de Carvalho. SUCEN. Rua Paula Souza 166, 01027-000 São Paulo, SP.

Telefax: 55 11 3311-1194

e-mail: esther@sucen.sp.gov.br, lorpa@uol.com.br
}

simultaneamente ao inquérito entre escolares dos anos 1973 a 1983, a primeira foi trabalhada entre 1976 e 1978 e a segunda, em 1980. O Programa de Controle da Doença de Chagas (PCDCh) no Estado de São Paulo encontrava-se na fase de controle do vetor denominada Prioridades, que se estendeu entre 1973 e 1982 e em que os municípios eram trabalhados de acordo com a presença ou ausência de seu principal vetor, T. infestans ${ }^{2,3,4}$. A seleção dessas microrregiões baseou-se em resultados de inquérito de prevalência da infecção chagásica realizado de 1968 a 1970, entre escolares ${ }^{1}$. Em Campos de Itapetininga, encontravam-se as prevalências mais elevadas do estado ${ }^{5}$, associadas à presença do $T$. infestans até o final da década de 60 e início da de 70. Na Encosta Ocidental da Mantiqueira Paulista, as áreas eram infestadas por T. infestans no passado ${ }^{6}$, hoje com predominância de Panstrongylus megistus (Burmeister, 1835).

A microrregião Campos de Itapetininga é composta pelos municípios: Angatuba, Barão de Antonina, Buri, Guareí, Itaberá, Itapetininga, Itapeva, Itaporanga, Itararé e Ribeirão Vermelho 
do Sul (hoje, Riversul) e a microrregião Encosta Ocidental da Mantiqueira Paulista, por: Águas da Prata, Caconde, Divinolândia, Itobi, Mococa, Espírito Santo do Pinhal, Santo Antônio do Jardim, São João da Boa Vista, São José do Rio Pardo, São Sebastião da Grama, Tapiratiba e Vargem Grande do Sul (Figura 1).

As populações das localidades selecionadas nessas duas microrregiões foram submetidas à investigação sorológica para infecção chagásica, como parte de um projeto denominado Quadro epidemiológico da doença de Chagas, estrutura agrária e programa de controle de vetores em São Paulo, integrado entre Superintendência de Controle de Endemias (SUCEN), órgão responsável pelas ações de controle de vetor, e Departamento de Medicina Preventiva da Faculdade de Medicina da Universidade de São Paulo (USP), parcialmente financiado pelo Conselho Nacional de Pesquisa (CNPq). Três aspectos foram abordados nesse Projeto: prevalência da infecção chagásica; relações entre a doença de Chagas e modificações de estrutura agrária e avaliação do Programa de Controle em uma perspectiva histórica. O trabalho visando a relacionar os resultados alcançados pelo programa de controle de vetor e as mudanças estruturais na agricultura e outras atividades produtivas, com especial destaque ao tipo de habitação das populações envolvidas, permitiu a produção de expressiva quantidade de informações, em sorologia, ora resgatadas.

Este trabalho tem como objetivo principal resgatar e analisar dados primários sobre sorologia da infecção chagásica nas populações humanas dessas duas microrregiões do Estado de São Paulo, entre os anos de 1976 e 1980, associando-os a presença do vetor T. infestans, consolidando o máximo de informações existentes sobre a situação epidemiológica da doença nesse período. Pretende-se a comparação de valores de positividade sorológica da infecção chagásica, por grupo etário, em áreas nas quais, segundo se admite, a interrupção da transmissão ocorreu em ocasiões diferentes nos municípios das duas microrregiões. Busca, ainda, definir a endemicidade das áreas segundo a distribuição de títulos das reações sorológicas em suas populações.

\section{MÉTODOS}

\section{Fonte de dados}

Dados primários de sorologia compõem registro do Laboratório de Imunoepidemiologia da SUCEN. Informações sobre presença de vetores foram buscadas em arquivos do Departamento de Combate a Vetores (DCV) da SUCEN ${ }^{7}$.

\section{Metodologia sorológica}

A técnica sorológica utilizada foi a da reação de imunofluorescência indireta (RIFI) ${ }^{8}$, com antígeno constituído por formas de cultivo de Trypanosoma cruzi fixadas em lâminas de microscopia ${ }^{9}$, preparadas no Laboratório ou adquiridas

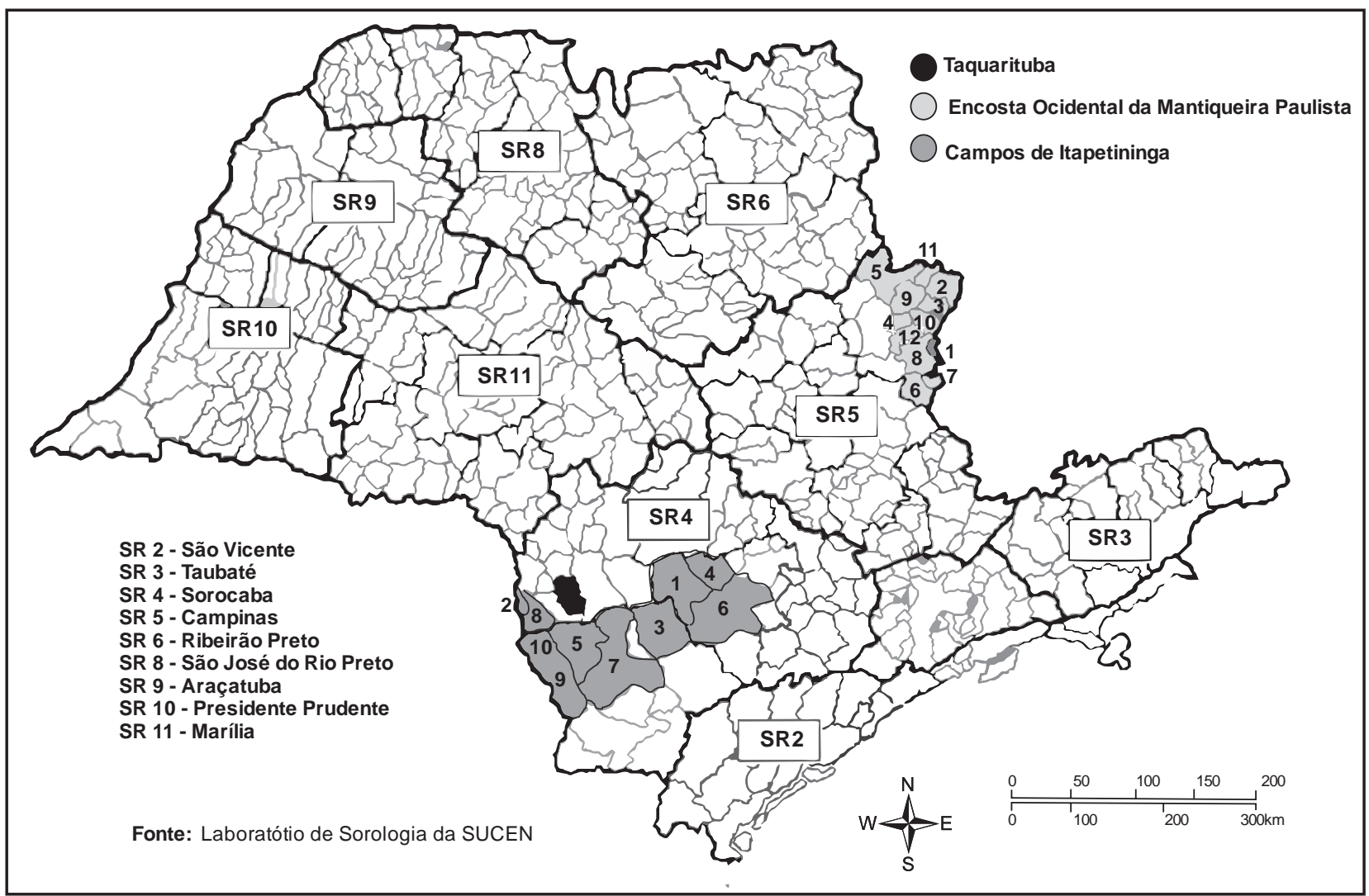

FIGURA 1 - Mapa do Estado de São Paulo (Meridiano Central 48³0’W de Greenwich - Paralelos padrões: 2040’S e 2420’'S) com indicação de municípios trabalhados: Taquarituba e das microrregiões Campos de Itapetininga (1- Angatuba; 2- Barão de Antonina; 3- Buri; 4- Guareí; 5- Itaberá; 6- Itapetininga; 7- Itapeva; 8- Itaporanga; 9- Itararé; 10- Riversul) e Encosta Ocidental da Mantiqueira Paulista (1- Águas da Prata; 2- Caconde; 3- Divinolândia; 4- Itobi; 5- Mococa; 6- Espírito Santo do Pinhal; 7- Santo Antônio do Jardim; 8- São João da Boa Vista; 9- São José do Rio Pardo; 10- São Sebastião da Grama; 11- Tapiratiba; 12- Vargem Grande do Sul), entre 1974 e 1980. 
comercialmente. Soros-controle positivos e negativos foram fornecidos pelo Setor de Xenodiagnóstico do Instituto Dante Pazzanese de Cardiologia, da Secretaria de Estado da Saúde de São Paulo. Sempre adquiridos no comércio, de preferência de fonte caprina, os conjugados anti-IgG humanos foram titulados para uso na máxima reatividade; contracoloração com azul de Evans a 1:10.000.

\section{Colheita de amostras de sangue}

Os inquéritos soroepidemiológicos realizaram-se com sangue colhido de polpa digital em papel de filtro de diferentes procedências. Inicialmente, usou-se o papel Klabin 80, substituído por Whatman no 1, equivalente em gramatura. Outra opção foi o papel Whatman $n^{\circ} 3$, que apresenta o dobro de absorção de sangue que o de $n^{\circ} 1$. O processo de eluição foi simplificado ${ }^{10}$ e a quantidade de sangue contida em área superficial unitária de papel-filtro foi calculada sempre que se passava a usar um novo lote ${ }^{11}$. As quantidades de sangue absorvidas por $\mathrm{cm}^{2}$ de papel variaram de 6,9-7,2 $\mu$ l de soro nos mais delgados e de 14,9 a $15,4 \mu \mathrm{l}$ de soro nos de maior gramatura.

\section{Diluições de corte}

Inicialmente, a diluição adotada foi 1:40, de acordo com o preconizado ${ }^{12}$. Com o objetivo de aumentar a sensibilidade das reações, mesmo em detrimento de perda de especificidade ${ }^{13}$, deliberamos usar a diluição de corte 1:20, conforme sugerem outros autores $^{14}$. Entretanto, passou-se a realizar habitualmente reações quantitativas, a fim de possibilitar a caracterização dos resultados dentro de seu espectro de distribuição e determinar a média geométrica dos títulos.

\section{Análise de dados}

Usaram-se bancos de dados em programa FoxPro ${ }^{\circledR}$ para Windows ${ }^{\circledR}$ incluindo as variáveis: Município, Localidade, Nome, idade, sexo, número da casa, tipo de moradia, tempo de moradia na casa, presença de barbeiros na casa, resultados de sorologia quantitativa (expressos em título). Para verificar-se a curva de endemicidade característica de cada microrregião, perfis sorológicos foram associados à distribuição de títulos das reações ${ }^{15}$. Testes de diferenças de proporções ${ }^{16}$ foram aplicados na comparação de prevalências por grupos etários específicos.

\section{RESULTADOS}

Entre 1976 e 1978, foram trabalhadas 15.117 amostras na microrregião Campos de Itapetininga, selecionadas a partir de população de 113.265 habitantes dos 10 municípios e de 322 localidades que a compunham, segundo plano de amostragem ${ }^{17}$. $\mathrm{Na}$ área da Encosta Ocidental da Mantiqueira Paulista foram processadas, em 1980, 16.351 amostras procedentes de 12 municípios e 142 localidades ${ }^{1}$.

\section{Microrregião Campos de Itapetininga}

Os dez municípios dessa microrregião distribuem-se pelas Regiões de Governo de Avaré, municípios: Barão de Antonina e Itaporanga; Itapetininga, municípios: Angatuba, Guareí e Itapetininga e Itapeva, municípios: Buri, Itaberá, Itapeva, Itararé e Riversul, por sua vez inseridos no Serviço Regional da SUCEN de Sorocaba (SR 4). Ocupam área de $9.591 \mathrm{~km}^{2}$ $(3,9 \% \text { do estado })^{18}$.

A Tabela 1 apresenta o total de amostras examinadas e reagentes para infecção chagásica, bem como o número de localidades existentes e trabalhadas. Os percentuais de reatividade variaram de 2,9 a 19,2, respectivamente, nos municípios Itararé e Itaporanga. A positividade na população em geral foi de $10,2 \%$.

Nas 55 localidades trabalhadas, a reatividade variou de 0,2 a $33,2 \%$, sendo que o resultado foi nulo apenas em uma delas, ou 1,8\% dos casos (Tabela 2).

A Tabela 3 mostra que a reatividade sorológica distribuiuse igualmente entre os sexos $(\mathrm{p}=0,130)$.

As idades da população trabalhada variaram de 1 mês a 94 anos, sendo a média igual a 22,8 anos, mediana, 17,0 anos, 25\% com até 8,0 anos e $75 \%$ com até 35,0 anos. Quanto à distribuição por sexo, 7.820 (51,7\%) foram do grupo feminino e 7.297 (48,3\%) do grupo masculino. No conjunto dos reagentes sorológicos, as idades variaram de 1 a 89 anos, com a média igual a 31,2 anos, mediana, 28,0 anos, $25 \%$ com até 20,0 anos e $75 \%$ com até 40,0 anos.

TABELA 1 - Sorologia para infecção chagásica na população rural da microrregião Campos de Itapetininga, Estado de São Paulo, 1976-1978.

\begin{tabular}{|c|c|c|c|c|c|c|c|}
\hline \multirow[b]{2}{*}{ Município } & \multirow{2}{*}{$\begin{array}{c}\text { Localidades } \\
\text { existentes* } \\
n^{\circ}\end{array}$} & \multicolumn{2}{|c|}{$\begin{array}{l}\text { Localidades } \\
\text { trabalhadas }\end{array}$} & \multirow{2}{*}{$\begin{array}{c}\text { Amostras } \\
\text { colhidas } \\
n^{\circ}\end{array}$} & \multicolumn{2}{|c|}{$\begin{array}{l}\text { Amostras } \\
\text { reagentes }\end{array}$} & \multirow{2}{*}{$\begin{array}{l}\text { Intervalo } \\
\text { confiança** }\end{array}$} \\
\hline & & $\mathrm{n}^{\circ}$ & $\%$ & & $\mathrm{n}^{\circ}$ & $\%$ & \\
\hline Angatuba & 35 & 5 & 14,3 & 1.215 & 116 & 9,5 & $8,02-11,33$ \\
\hline Barão de Antonina & 9 & 1 & 11,1 & 158 & 26 & 16,5 & $11,48-23,02$ \\
\hline Buri & 27 & 3 & 11,1 & 487 & 17 & 3,5 & $2,19-5,52$ \\
\hline Guareí & 21 & 4 & 19,1 & 703 & 45 & 6,4 & $4,82-8,46$ \\
\hline Itaberá & 39 & 10 & 25,6 & 3.014 & 552 & 18,3 & $16,97-19,74$ \\
\hline Itapetininga & 70 & 11 & 15,7 & 2.513 & 114 & 4,5 & $3,79-5,42$ \\
\hline Itapeva & 42 & 7 & 16,7 & 3.230 & 291 & 9,0 & $8,07-10,05$ \\
\hline Itaporanga & 24 & 4 & 16,7 & 1.441 & 277 & 19,2 & $17,27-21,34$ \\
\hline Itararé & 43 & 6 & 13,9 & 1.557 & 45 & 2,9 & $2,17-3,85$ \\
\hline Riversul & 23 & 4 & 17,4 & 799 & 60 & 7,5 & $5,88-9,55$ \\
\hline Total & 333 & 55 & 16,5 & 15.117 & 1.543 & 10,2 & $9,73-10,70$ \\
\hline
\end{tabular}


TABELA 2 - Sorologia para infecção chagásica em localidades dos municípios da microrregião Campos de Itapetininga, Estado de São Paulo, 1976-1978.

\begin{tabular}{|c|c|c|c|c|c|c|c|}
\hline \multirow[b]{2}{*}{ Localidade } & \multirow{2}{*}{$\begin{array}{c}\text { Amostra examinada } \\
\mathrm{n}^{\circ}\end{array}$} & \multicolumn{2}{|c|}{ Amostras reagentes } & \multirow[b]{2}{*}{ Localidade } & \multirow{2}{*}{$\begin{array}{c}\text { Amostra examinada } \\
\mathrm{n}^{\circ}-\end{array}$} & \multicolumn{2}{|c|}{ Amostras reagentes } \\
\hline & & $\mathrm{n}^{\circ}$ & $\%$ & & & $\mathrm{n}^{\circ}$ & $\%$ \\
\hline Angatuba & & & & Itapetininga (continua) & & & \\
\hline Bairro dos Buenos & 177 & 8 & 4,5 & Bairro Chapada Gde. & 695 & 34 & 4,9 \\
\hline Bairro dos Nunes & 123 & 7 & 5,7 & Bairro dos Elias & 66 & 6 & 9,1 \\
\hline Bairro do Salto & 515 & 65 & 12,6 & Bairro dos Soares & 327 & 10 & 3,1 \\
\hline Faz. União & 127 & 11 & 8,7 & Bairro Sabiá Una & 280 & 5 & 1,8 \\
\hline Bairro Ribeirão Grande & 273 & 25 & 9,2 & Bairro Tijuco Preto & 295 & 12 & 4,1 \\
\hline Barão de Antonina & & & & Faz. Sta. Luzia & 40 & 1 & 2,5 \\
\hline Bairro Barragem & 158 & 26 & 16,5 & Faz. São João & 99 & 9 & 9,1 \\
\hline Buri & & & & Itapeva & & & \\
\hline Bairro Enxovia & 136 & 4 & 2,9 & Bairro Amarela Velha & 661 & 114 & 17,2 \\
\hline Bairro Fundão & 110 & 1 & 0,9 & Bairro Areia Branca & 889 & 61 & 6,9 \\
\hline Bairro Vitorino Camilo & 241 & 12 & 5,0 & Bairro da Sanbra & 330 & 17 & 5,1 \\
\hline Guareí & & & & Bairro da Serrinha & 475 & 23 & 4,8 \\
\hline Bairro da Areia Branca & 286 & 25 & 8,7 & Bairro Estação de Jaó & 240 & 22 & 9,2 \\
\hline Bairro da Capela Velha & 87 & 5 & 5,7 & Bairro Mato Dentro & 247 & 19 & 7,7 \\
\hline Bairro dos Lemes & 82 & 5 & 6,1 & Faz. Barreiro Gde. & 388 & 37 & 9,5 \\
\hline Bairro do Rincão & 248 & 10 & 4,0 & Itaporanga & & & \\
\hline Itaberá & & & & Bairro Barra da Onça & 447 & 100 & 0,2 \\
\hline Bairro Água Amarela & 872 & 144 & 16,5 & Bairro Capituva & 64 & 10 & 15,6 \\
\hline Bairro Est. Engo Maia & 497 & 71 & 14,3 & Bairro do Soalho & 306 & 79 & 25,8 \\
\hline Bairro Limeira & 413 & 75 & 18,2 & Bairro Lageado & 624 & 88 & 14,1 \\
\hline Bairro Mangueiro Gde. & 356 & 118 & 33,2 & Itararé & & & \\
\hline Bairro Mestre Pedro & 118 & 5 & 4,2 & Bairro Embuia & 75 & 4 & 5,3 \\
\hline Bairro Passa Três & 143 & 43 & 30,1 & Bairro Ibiti Sorocabana & 48 & 4 & 8,3 \\
\hline Bairro Pirituba & 337 & 65 & 19,3 & Bairro Cerrado & 535 & 27 & 5,1 \\
\hline Bairro Ponte Alta & 69 & 8 & 11,6 & Bairro Bom Sucesso & 269 & 2 & 0,7 \\
\hline Bairro Ribeirão Bairronito & 53 & 7 & 13,2 & Bairro Itambé & 447 & 3 & 0,7 \\
\hline Bairro Sta. Izabel & 156 & 16 & 10,3 & Bairro Serrinha I & 183 & 5 & 2,7 \\
\hline Itapetininga & & & & Riversul & & & \\
\hline Bairro Bernardi & 190 & 20 & 10,5 & Bairro da Lagem & 28 & 0 & 0,0 \\
\hline Bairro Campo Grande & 274 & 10 & 3,6 & Bairro Morro Alto & 178 & 6 & 3,4 \\
\hline Bairro Capivari & 89 & 1 & 1,1 & Bairro Can Can & 178 & 8 & 4,5 \\
\hline Bairro Cesário & 158 & 6 & 3,8 & Bairro Sapezal & 415 & 46 & 11,1 \\
\hline
\end{tabular}

TABELA 3 - Sororreatividade para infecção chagásica na população de zona rural dos municípios da microrregião Campos de Itapetininga, Estado de São Paulo, 1976-1978.

\begin{tabular}{|c|c|c|c|c|c|c|c|c|c|}
\hline \multirow[b]{3}{*}{ Grupo etário anos } & \multicolumn{3}{|c|}{ Feminino } & \multicolumn{3}{|c|}{ Masculino } & \multicolumn{3}{|c|}{ Feminino + Masculino } \\
\hline & \multirow{2}{*}{$\begin{array}{c}\text { Amostras } \\
\text { examinadas } \\
n^{\circ}-\end{array}$} & \multicolumn{2}{|c|}{$\begin{array}{l}\text { Amostras } \\
\text { reagentes }\end{array}$} & \multirow{2}{*}{$\begin{array}{c}\text { Amostras } \\
\text { examinadas } \\
n^{\circ}\end{array}$} & \multicolumn{2}{|c|}{$\begin{array}{l}\text { Amostras } \\
\text { reagentes }\end{array}$} & \multirow{2}{*}{$\begin{array}{c}\text { Amostras } \\
\text { examinadas } \\
\mathrm{n}^{\circ} \\
\end{array}$} & \multicolumn{2}{|c|}{$\begin{array}{l}\text { Amostras } \\
\text { reagentes }\end{array}$} \\
\hline & & $\mathrm{n}^{\circ}$ & $\%$ & & $\mathrm{n}^{0}$ & $\%$ & & $\mathrm{n}^{\circ}$ & $\%$ \\
\hline$<1$ & 136 & 0 & 0,0 & 122 & 0 & 0,0 & 258 & 0 & 0,0 \\
\hline $1-4$ & 956 & 11 & 1,1 & 989 & 9 & 0,9 & 1.945 & 20 & 1,0 \\
\hline $5-9$ & 1.303 & 26 & 2,0 & 1.252 & 19 & 1,5 & 2.555 & 45 & 1,8 \\
\hline $10-14$ & 1.091 & 77 & 7,1 & 1.038 & 54 & 5,2 & 2.129 & 131 & 6,2 \\
\hline $15-19$ & 765 & 87 & 11,4 & 667 & 87 & 13,0 & 1.432 & 174 & 12,2 \\
\hline $20-29$ & 1.164 & 216 & 18,6 & 941 & 229 & 24,3 & 2.105 & 445 & 21,1 \\
\hline $30-39$ & 904 & 159 & 17,6 & 709 & 161 & 22,7 & 1.613 & 320 & 19,8 \\
\hline $40-49$ & 686 & 97 & 14,1 & 608 & 109 & 17,9 & 1.294 & 206 & 15,9 \\
\hline $50-59$ & 426 & 57 & 13,4 & 468 & 44 & 9,4 & 894 & 101 & 11,3 \\
\hline $60-69$ & 278 & 29 & 10,4 & 339 & 41 & 12,1 & 617 & 70 & 11,3 \\
\hline$\geq 70$ & 111 & 11 & 9,9 & 164 & 20 & 12,2 & 275 & 31 & 11,3 \\
\hline Total & 7.820 & 770 & 9,8 & 7.297 & 773 & 10,6 & 15.117 & 1.543 & 10,2 \\
\hline
\end{tabular}


A Figura 2, que se exibe adiante, fornece a distribuição de frequência de reatividade sorológica para infecção chagásica segundo grupos etários. Nota-se, para a microrregião Campos de Itapetininga (SR4), uma ascensão até o grupo 20-29 anos, seguida de declínio nos demais grupos, permanecendo praticamente invariável nas idades acima de 49 anos.

Do mesmo modo observamos na Figura 3, para a microrregião Campos de Itapetininga (SR4), uma curva bimodal de distribuição de frequências de títulos sorológicos para infecção chagásica, no período 1976-1978. A média geométrica de títulos dos reagentes foi igual a 100, tendo variado de 20 a 5.120.

$\mathrm{Na}$ população geral ( $\left.\mathrm{n}^{\circ}=14.327\right)$, o tempo de moradia na residência atual foi de 5,8 anos em média, mediana de 3,0 anos, $25 \%$ com até 1,0 ano e $75 \%$ com até 8,0 anos. No grupo dos sororreagentes $\left(\mathrm{n}^{\mathrm{Q}}=1.516\right)$ os valores não foram significativamente diferentes: média igual a 5,9 anos e demais com os mesmos valores do grupo geral da população. Em ambas as situações, foram subtraídos os casos em que não se dispôs

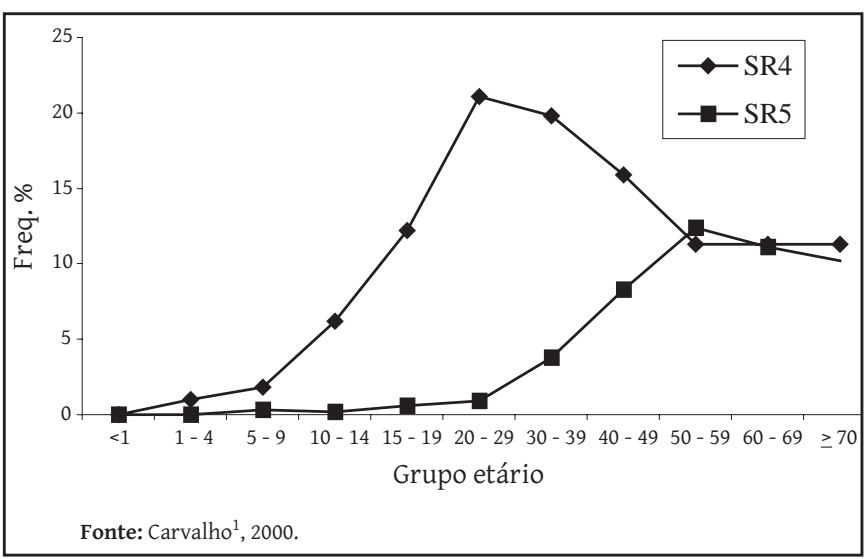

FIGURA 2 - Distribuição de frequência percentual de sororreatividade para infecção chagásica, por grupos etários, das populações dos municípios das microrregiões Campos de Itapetininga (SR4) e Encosta Ocidental da Mantiqueira Paulista (SR5), entre 1976 e 1980.

TABELA 4 - Sorologia para infecção chagásica na população rural da microrregião Encosta Ocidental da Mantiqueira Paulista, Estado de São Paulo, 1980.

\begin{tabular}{|c|c|c|c|c|c|c|c|}
\hline \multirow[b]{2}{*}{ Município } & \multirow{2}{*}{$\begin{array}{c}\text { Localidades } \\
\text { existentes* } \\
\text { nº }\end{array}$} & \multicolumn{2}{|c|}{$\begin{array}{l}\text { Localidades } \\
\text { trabalhadas }\end{array}$} & \multirow{2}{*}{$\begin{array}{c}\text { Amostras } \\
\text { colhidas } \\
\mathrm{n}^{\circ}{ }^{\circ}\end{array}$} & \multicolumn{2}{|c|}{$\begin{array}{l}\text { Amostras } \\
\text { reagentes }\end{array}$} & \multirow{2}{*}{$\begin{array}{c}\mathrm{IC}^{* *} \text { dos } \\
\text { reagentes } \\
\%\end{array}$} \\
\hline & & $\mathrm{n}^{\circ}$ & $\%$ & & $\mathrm{n}^{\circ}$ & $\%$ & \\
\hline Águas da Prata & 21 & 5 & 23,8 & 794 & 8 & 1,0 & $0,51-1,98$ \\
\hline Caconde & 61 & 13 & 21,3 & 2.371 & 157 & 6,6 & $5,69-7,69$ \\
\hline Divinolândia & 32 & 7 & 21,9 & 1.278 & 35 & 2,7 & $1,98-3,78$ \\
\hline Espírito Santo Pinhal & 67 & 14 & 20,9 & 1.002 & 19 & 1,9 & $1,22-2,94$ \\
\hline Itobi & 32 & 5 & 15,6 & 288 & 10 & 3,5 & $1,90-6,27$ \\
\hline Mococa & 64 & 16 & 25,0 & 2.822 & 101 & 3,6 & $2,95-4,33$ \\
\hline Sto Antônio Jardim & 27 & 7 & 25,9 & 773 & 6 & 0,8 & $0,36-1,68$ \\
\hline São João Boa Vista & 137 & 34 & 24,8 & 2.685 & 53 & 2,0 & $1,51-2,57$ \\
\hline São José Rio Pardo & 89 & 19 & 21,4 & 2.301 & 43 & 1,9 & $1,39-2,51$ \\
\hline S Sebastião Grama & 45 & 10 & 22,2 & 820 & 20 & 2,4 & $1,58-3,74$ \\
\hline Tapiratiba & 22 & 5 & 22,7 & 596 & 26 & 4,4 & $2,99-6,32$ \\
\hline Vargem Grande de Sul & 39 & 9 & 23,1 & 621 & 12 & 1,9 & $1,11-3,35$ \\
\hline Total & 636 & 144 & 22,6 & 16.351 & 490 & 3,0 & $2,75-3,27$ \\
\hline
\end{tabular}

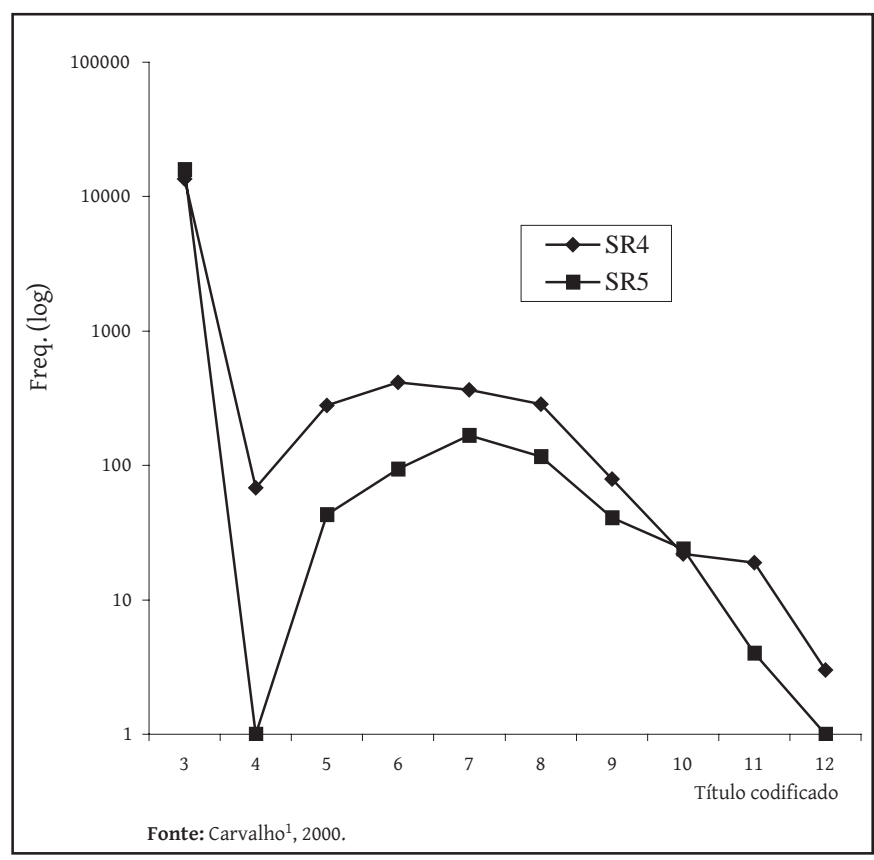

FIGURA 3 - Distribuição de frequência de títulos de reação de imunofluorescência indireta para infecção chagásica, de população dos municípios das microrregiões Campos de Itapetininga (SR4) e Encosta Ocidental da Mantiqueira Paulista (SR5), entre 1976 e 1980. Títulos codificados: $3 \leq 20 ; 4=20 ; 5=40 ; 6=80 ; 7=160 ; 8=320 ; 9=640 ; 10=1.280$; $11=2.560 ; 12=5.120$.

das informações sobre tempo de moradia, respectivamente 790 e 27 amostras. Em 2.410 (16,8\%) casos, o tempo de moradia na casa foi igual à idade. Nessa condição, a média da idade (e do tempo de moradia) foi de 8,1 anos, mediana, 5,0 anos, $25 \%$ com até 2,0 anos e $75 \%$ com até 11,0 anos.

\section{Microrregião Encosta Ocidental da Mantiqueira Paulista}

Os doze municípios dessa microrregião: Águas da Prata, Caconde, Divinolândia, Espírito Santo do Pinhal, Itobi, Mococa, Santo Antônio do Jardim, São João da Boa Vista, São José do Rio Pardo, São Sebastião da Grama, Tapiratiba e Vargem Grande do Sul pertencem a uma única Região de Governo, de São João da Boa Vista, do Serviço Regional da SUCEN de Campinas (SR-5). Ocupam área de $3.989 \mathrm{~km}^{2}$ (1,6\% do estado $)^{18}$.

A Tabela 4 apresenta o total de amostras examinadas e reagentes para infecção chagásica e o número de localidades existentes e trabalhadas. Os percentuais de reatividade variaram de 0,8 a 6,6, respectivamente nos municípios Santo Antônio do Jardim e Caconde. A positividade na população em geral foi de $3 \%$.

Nas 144 localidades trabalhadas, a reatividade variou de 0,0 a $11,6 \%$ (Tabela 5).

Conforme mostra a Tabela $\mathbf{6}$, as idades da população trabalhada 
TABELA 5 - Sorologia para infecção chagásica em localidades dos municípios da microrregião Encosta Ocidental da Mantiqueira Paulista, Estado de São Paulo, 1980.

\begin{tabular}{|c|c|c|c|c|c|c|c|c|c|c|c|}
\hline \multirow[b]{2}{*}{ Localidade } & \multirow{2}{*}{$\begin{array}{c}\text { Amostra } \\
\text { examinada } \\
n^{\circ}{ }^{\circ}\end{array}$} & \multicolumn{2}{|c|}{$\begin{array}{l}\text { Amostras } \\
\text { reagentes }\end{array}$} & \multirow[b]{2}{*}{ Localidade } & \multirow{2}{*}{$\begin{array}{c}\text { Amostra } \\
\text { examinada } \\
n^{\circ}-\end{array}$} & \multicolumn{2}{|c|}{$\begin{array}{l}\text { Amostras } \\
\text { reagentes }\end{array}$} & \multirow[b]{2}{*}{ Localidade } & \multirow{2}{*}{$\begin{array}{c}\text { Amostra } \\
\text { examinada } \\
\mathrm{n}^{\circ}\end{array}$} & \multicolumn{2}{|c|}{$\begin{array}{l}\text { Amostras } \\
\text { reagentes }\end{array}$} \\
\hline & & $\mathrm{n}^{\circ}$ & $\%$ & & & $\mathrm{n}^{\circ}$ & $\%$ & & & $\mathrm{n}^{\circ}$ & $\%$ \\
\hline Águas da Prata & & & & Mococa & & & & São João da Boa Vista & & & \\
\hline Faz. Sta. Maria & 55 & 0 & 0,0 & Faz. Do Porto & 113 & 8 & 7,1 & Faz. Morro Alto & 32 & 1 & 3,1 \\
\hline Bairro São Roque & 557 & 6 & 1,1 & Chácara Recreio & 8 & 0 & 0,0 & Bairro Campo Redondo & 46 & 5 & 10,9 \\
\hline Faz. Prata & 54 & 0 & 0,0 & Bairro Ressaca & 23 & 1 & 4,3 & Faz. Olaria Jaguary & 30 & 0 & 0,0 \\
\hline Faz. Prata & 54 & 0 & 0,0 & Faz. Pessegueiro & 89 & 7 & 7,9 & Faz. Belém & 15 & 0 & 0,0 \\
\hline Bairro Sobradinho & 24 & 1 & 4,2 & BCambuí & 240 & 2 & 0,8 & Faz. Larandeiro & 28 & 0 & 0,0 \\
\hline Periferia & 104 & 1 & 1,0 & B ${ }^{\circ}$ Sto. Antônio & 122 & 0 & 0,0 & Bairro Cachoeirinha II & 101 & 9 & 8,9 \\
\hline Caconde & & & & Faz.Sta Clara Serra & 88 & 3 & 3,4 & São José do Rio Pardo & & & \\
\hline Bairro Bom Jesus & 260 & 28 & 10,8 & Di.S.Bened. Areias & 508 & 26 & 5,1 & Faz. Sta. Helena & 137 & 1 & 0,7 \\
\hline Bairro Conceição & 81 & 2 & 2,5 & Faz. Rozinha & 11 & 0 & 0,0 & Faz. Cór. do Veado & 8 & 0 & 0,0 \\
\hline Faz. São Carlos & 100 & 10 & 10,0 & Periferia & 450 & 23 & 5,1 & Faz. Sta. Matilde & 145 & 3 & 2,1 \\
\hline Bairro Braço Grande & 32 & 0 & 0,0 & Faz. São Bento & 277 & 9 & 3,2 & Faz. Cascalho & 56 & 2 & 3,6 \\
\hline Faz. Boa Vista & 66 & 2 & 3,0 & Faz. Morro Azul & 474 & 15 & 3,2 & Faz. Água Fria & 97 & 0 & 0,0 \\
\hline Bairro Cór. da Vaca & 60 & 6 & 10,0 & Faz. Alagoas & 79 & 0 & 0,0 & Bairro Muladeiro & 137 & 6 & 4,4 \\
\hline Periferia & 1.090 & 80 & 7,3 & Faz. Cafezal & 186 & 7 & 3,7 & Faz. Est. V.Costina & 455 & 10 & 2,2 \\
\hline Bairro Sta. Quitéria & 86 & 8 & 9,3 & $\mathrm{~B}^{\circ}$ Caixeta I & 152 & 0 & 0,0 & Bairro Sueiro & 40 & 0 & 0,0 \\
\hline Faz. Barra Grande & 49 & 0 & & Faz. Sta Eustáquia & 10 & 0 & 0,0 & Faz. Sta. Maria I & 39 & 1 & 2,6 \\
\hline Faz. Zambuja & 122 & & 0,0 & Santo Antônio do Jardim & & & & Faz. Sta. Luzia & 53 & 1 & 1,9 \\
\hline az. Lainuza & 132 & 6 & 4,5 & Faz. Sta. Bárbara & 85 & 2 & 2,3 & Faz. Tubaca & 115 & 2 & 1,7 \\
\hline Faz. Barreiro & 54 & 2 & 3,7 & Bairro Sta. Bárbara I & 161 & 0 & 0,0 & Faz. Viradouro & 39 & 0 & 0,0 \\
\hline Bairro Cór. do Engano & 90 & 8 & 8,9 & Bairro Sta. Maria & 50 & 0 & 0,0 & Bairro N. Sra. de Fátima & 97 & 1 & 1,0 \\
\hline Bairro Vila Barrânia & 270 & 5 & 1,8 & Faz. Santana & 30 & 0 & 0,0 & Faz. Ouro Branco & 41 & 2 & 4,9 \\
\hline Divinolândia & & & & Periferia & 225 & 2 & 0,9 & Faz. Vila Maria & 118 & 6 & 5,1 \\
\hline Periferia & 319 & 16 & 5,0 & Faz.Ret.Sto Antônio & 118 & 1 & 0,8 & Faz. Modelo & 43 & 1 & 2,3 \\
\hline Bairro Campestrinho & 359 & 4 & 1,1 & Bairro da Manteiga & 96 & 1 & 1,0 & Bairro Barreir. Gabiroba & a 24 & 0 & 0,0 \\
\hline Bairro Conceição & 118 & 4 & 3,4 & São João da Boa Vista & & & & Bairro Sítio Novo & 263 & 5 & 1,9 \\
\hline Bairro Pinhalzinho & 152 & 1 & 0,7 & $\mathrm{Pe}$ & 906 & 11 & 1,2 & Faz. Santa Lúcia & 394 & 2 & 0,5 \\
\hline Pirapitinga III & 77 & 6 & 7,8 & Faz. Ribeirão & 14 & 1 & 7,1 & São Sebastião da Grama & & & \\
\hline Bairro Vargem Grande & 234 & 4 & 1,7 & Faz. Da Barra & 24 & 2 & 8,3 & Bairro Campinho & 34 & 2 & 5,9 \\
\hline Bairro Plaino Alto & 19 & 0 & 0,0 & $\begin{array}{l}\text { Bairro Jaguari } \\
\text { Sítio São Pedro }\end{array}$ & 90 & 1 & 1,1 & Bairro Bom Jardim & 43 & 5 & 11,6 \\
\hline Espírito Santo do Pinhal & & & & $\begin{array}{l}\text { Sit1o Sao Pedro } \\
\text { Faz. Matãozinho }\end{array}$ & $\begin{array}{l}36 \\
36\end{array}$ & $\begin{array}{l}1 \\
0\end{array}$ & $\begin{array}{l}2,8 \\
0,0\end{array}$ & Bairro Cachoeirinha & 42 & 2 & 4,8 \\
\hline Faz. Sta. Vitória & 78 & 0 & 0,0 & Fda. Sta. Izabel & 19 & 2 & 10,5 & $\begin{array}{l}\text { Bairro Cocal } \\
\text { Bairro Farturinha }\end{array}$ & $\begin{array}{l}64 \\
79\end{array}$ & $\begin{array}{l}1 \\
3\end{array}$ & $\begin{array}{l}1,6 \\
3,8\end{array}$ \\
\hline Faz. São João II & 73 & 0 & 0,0 & Bairro Campo Belo & 139 & 3 & 2,2 & Bairro Água Vertente & 30 & 0 & 0,0 \\
\hline Faz. Sta. Tereza II & 76 & 1 & 1,3 & Faz. Matão & 135 & 3 & 2,2 & Faz. São Benedito & 8 & 0 & 0,0 \\
\hline Bairro das Poças & 148 & 8 & 5,4 & Bairro Estiva & 78 & 1 & 1,3 & Bairro Serrinha & 43 & 3 & 7,0 \\
\hline Faz Sto Ant. Jangada & 48 & 0 & 0,0 & Faz. São Geraldo & 133 & 3 & 2,3 & Faz. Água Limpa & 255 & 3 & 1,2 \\
\hline Faz. Vila Verde & 21 & 1 & 4.8 & Bairro Paradouro & 29 & 0 & 0,0 & Bairro São Domingos & 223 & 1 & 0,4 \\
\hline Bairro Catingueiro & 139 & 3 & , & Bairro Mamonal & 156 & 0 & 0,0 & Tapiratiba & & & \\
\hline Faz. Sta. Maria & 21 & 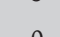 & & Faz. São Joaquim & 35 & 0 & 0,0 & Periferia & 90 & 4 & 4,4 \\
\hline Faz. Sto. Antonio III & 21 & 0 & 0,0 & Bairro Demanda & 67 & 1 & 1,5 & Bairro Macaúba & 115 & 3 & 2,6 \\
\hline Faz Sta. Hélida & 72 & 0 & 0,0 & Faz. da Lage & 95 & 1 & 1,1 & Faz. Bela Vista & 170 & 12 & 7,1 \\
\hline & 120 & 0 & 0,0 & Faz. Aliança & 34 & 1 & 2,9 & Faz. Santo Antônio & 119 & 5 & 4,2 \\
\hline Faz. Imbiruçu & 30 & 2 & 6,7 & Bairro Lagoa dos Patos & 32 & 0 & 0,0 & Faz. Vila Flor & 102 & 2 & 2,0 \\
\hline Bairro Areião & 103 & 4 & 3,9 & Bairro Serra dos Padres & 10 & 0 & 0,0 & Vargem Grande do Sul & & & \\
\hline Faz. Sto. Antonio II & 29 & 1 & 3,4 & Sítio Boa Vista & 6 & 0 & 0,0 & Bairro Fortaleza & 48 & 2 & 4,2 \\
\hline Faz. Guarani & 44 & 0 & 0,0 & Sta. Margar & & 0 & 0,0 & Faz. Barreirinho & 95 & 1 & 1,1 \\
\hline Itobi & & & & $\begin{array}{l}\text { Bairro Boa Vista } \\
\text { Bairro Cór. Fund }\end{array}$ & 70 & 4 & 5,7 & Bairro Retirão & 121 & 6 & 5,0 \\
\hline Faz. Rio Doce & 101 & 4 & 4,0 & Bairro Taquaral & $\begin{array}{l}48 \\
15\end{array}$ & $\begin{array}{l}1 \\
1\end{array}$ & $\begin{array}{l}2,1 \\
6,7\end{array}$ & Bairro das Olarias & 72 & 1 & 1,4 \\
\hline Faz. Sta Cândida & 58 & 2 & 3,4 & Bairro Pedregulho I & 31 & 1 & 3.2 & Bairro Pinhalzinho & 58 & 0 & 0,0 \\
\hline Faz. Rio Doce Cima & 82 & 4 & 4,9 & Faz. Campo Novo & 98 & 0 & 0,0 & Bairro Cór. Raso & 35 & 0 & 0,0 \\
\hline Bairro Sítio São João & 12 & 0 & 0,0 & Faz. Coqueiro & 54 & 0 & 0,0 & Faz. Floresta & 60 & 1 & 1,7 \\
\hline Faz. Sto. Antônio & 35 & 0 & 0,0 & Bairro Serrinha & 15 & 0 & 0 & Faz. Chapadão & 36 & 0 & 0,0 \\
\hline
\end{tabular}


TABELA 6 - Sororreatividade para infecção chagásica na população de zona rural dos municípios da microrregião Encosta Ocidental da Mantiqueira Paulista, Estado de São Paulo, 1980.

\begin{tabular}{|c|c|c|c|c|c|c|c|c|c|}
\hline \multirow[b]{3}{*}{ Grupo etário anos } & \multicolumn{3}{|c|}{ Feminino } & \multicolumn{3}{|c|}{ Masculino } & \multicolumn{3}{|c|}{ Feminino + Masculino } \\
\hline & \multirow{2}{*}{$\begin{array}{c}\text { Amostras } \\
\text { examinadas } \\
\mathrm{n}^{\circ} \mathrm{e}\end{array}$} & \multicolumn{2}{|c|}{$\begin{array}{l}\text { Amostras } \\
\text { reagentes }\end{array}$} & \multirow{2}{*}{$\begin{array}{c}\text { Amostras } \\
\text { examinadas } \\
\mathrm{n}^{\circ}{ }^{\circ}\end{array}$} & \multicolumn{2}{|c|}{$\begin{array}{l}\text { Amostras } \\
\text { reagentes }\end{array}$} & \multirow{2}{*}{$\begin{array}{c}\text { Amostras } \\
\text { examinadas } \\
\mathrm{n}^{\circ} \mathrm{o}\end{array}$} & \multicolumn{2}{|c|}{$\begin{array}{l}\text { Amostras } \\
\text { reagentes }\end{array}$} \\
\hline & & $\mathrm{n}^{\circ}$ & $\%$ & & $\mathrm{n}^{\circ}$ & $\%$ & & $\mathrm{n}^{\circ}$ & $\%$ \\
\hline$<1$ & 25 & 0 & 0,0 & 25 & 0 & 0,0 & 50 & 0 & 0,0 \\
\hline $1-4$ & 787 & 1 & 0,1 & 789 & 2 & 0,3 & 1.576 & 3 & 0,2 \\
\hline $5-9$ & 1.375 & 3 & 0,2 & 1.348 & 4 & 0,3 & 2.723 & 7 & 0,3 \\
\hline $10-14$ & 1.158 & 1 & 0,1 & 1.214 & 3 & 0,2 & 2.372 & 4 & 0,2 \\
\hline $15-19$ & 843 & 4 & 0,5 & 741 & 5 & 0,7 & 1.584 & 9 & 0,6 \\
\hline $20-29$ & 1.436 & 15 & 1,0 & 1.148 & 9 & 0,8 & 2.584 & 24 & 0,9 \\
\hline $30-39$ & 1.019 & 41 & 4,0 & 800 & 28 & 3,5 & 1.819 & 69 & 3,8 \\
\hline $40-49$ & 833 & 73 & 8,8 & 701 & 55 & 7,8 & 1.534 & 128 & 8,3 \\
\hline $50-59$ & 588 & 61 & 10,4 & 530 & 78 & 14,7 & 1.118 & 139 & 12,4 \\
\hline $60-69$ & 333 & 42 & 12,6 & 305 & 29 & 9,5 & 638 & 71 & 11,1 \\
\hline$\geq 70$ & 167 & 14 & 8,4 & 185 & 22 & 11,9 & 352 & 36 & 10,2 \\
\hline Total & 8.564 & 255 & 3,0 & 7.786 & 235 & 3,0 & 16.350 & 790 & 3,0 \\
\hline
\end{tabular}

variaram de 3 meses a 97 anos, sendo a média igual a 24,4 anos, mediana, 19,0 anos, $25 \%$ com até 9,0 anos e $75 \%$ com até 37,0 anos. Quanto à distribuição por sexo, 8.565 (52,4\%) foram do grupo feminino e $7.786(47,6 \%)$ do grupo masculino. No conjunto dos reagentes sorológicos, as idades variaram de 2 a 97 anos, com a média igual a 48,6 anos, mediana, 50,0 anos, $25 \%$ com até 40,0 anos e $75 \%$ com até 58,0 anos. A reatividade sorológica distribuiu-se igualmente entre os sexos $(p=0,878)$. Em relação à positividade observada na microrregião Campos de Itapetininga, houve diferença significante $(p \cong 0,000)$.

A distribuição de frequência de reatividade sorológica para infecção chagásica, por grupos etários, para a microrregião Encosta Ocidental da Mantiqueira Paulista, está apresentada na Figura 2, como SR5. A curva é ascendente até o grupo 50-59 anos, declinando discretamente nas idades superiores.

Da mesma maneira, como foi observado na microrregião Campos de Itapetininga, a curva de distribuição de frequências de títulos sorológicos para infecção chagásica, na população trabalhada na microrregião Encosta Ocidental da Mantiqueira Paulista (SR5), em 1980, foi bimodal (Figura 3). A média geométrica de títulos dos reagentes foi igual a 165 , tendo variado de 20 a 2.560 .

$\mathrm{Na}$ população geral $\left(\mathrm{n}^{\circ}=16.276\right)$, o tempo de moradia na residência atual variou de 1 dia a 86 anos, com uma média de 7,1 anos, mediana de 3,0 anos, $25 \%$ com até 1,0 ano e $75 \%$ com até 9,0 anos. No grupo dos sororreagentes $\left(\mathrm{n}^{\mathrm{0}}=490\right)$, os tempos de moradia variaram de 8 dias a 71 anos, com a média igual a 10,8 anos, mediana, 5,0 anos, $25 \%$ com até 1 ano e $75 \%$ dos casos com até 16 anos de residência. Em 3.090 casos (18,9\%), o tempo de moradia na casa foi igual à idade. Nessa condição, a média da idade (e do tempo de moradia) foi de 12,9 anos, mediana, 9,0 anos, $25 \%$ com até 4,0 anos e $75 \%$ com até 16,0 anos.

\section{DISCUSSÃo}

Da microrregião Campos de Itapetininga, na década de 1950, trabalho realizado nos municípios de Angatuba, Itapetininga e Itaporanga (que incluía os então Distritos de Barão de Antonina e Ribeirão Vermelho do Sul) ${ }^{19}$, demonstrou os valores de $27,7 \%, 15,2 \%$ e 30,4\% de positividade para a infecção chagásica, respectivamente ${ }^{20}$. Em Itapeva e Itararé, esse trabalho não observou positividade; entretanto, a amostra examinada foi insuficiente para representar o quadro real das repercussões humanas da transmissão da doença de Chagas. Nos municípios de Buri e Guareí, não foram examinadas amostras de sangue da população nessa época. Já, em 1958, os municípios com sororreativos para infecção chagásica: Angatuba, Itaberá, Itapetininga, Itapeva, Itaporanga (com Barão de Antonina) e Itararé haviam sido listados, encontrando-se a presença de T. infestans nos municípios de Buri, Guareí e Riversull ${ }^{21}$.

A despeito da falta de informações sobre naturalidade e tempo de permanência de seus habitantes na área, infere-se, a partir de dados populacionais da Região de Sorocaba, que ocorreram nesta as menores variações observadas no estado, entre os anos de 1960 e 1970, sem perdas importantes por evasões ${ }^{22}$. Buri, Itaberá, Itapeva, Itararé e Riversul situam-se na Região de Governo Itapeva, que equilibrou sua população, nos anos 70, com evasão e crescimento vegetativo; Angatuba, Itapetininga e Guareí, da Região de Governo Itapetininga, com o componente de crescimento vegetativo apenas e Barão de Antonina e Itaporanga, da Região de Governo Avaré, com crescimento populacional em que teve maior peso o componente migratório ${ }^{18}$.

A sororreatividade dos grupos etários superiores a 20 anos evidencia a intensa exposição à transmissão a que foram submetidos os habitantes de Campos de Itapetininga nascidos antes de 1956. O valor médio de idade dos sororreagentes, 31,2 anos, permite situar suas datas de nascimento entre 1945 e 1947. Mesmo assim, as faixas de idades menores que 20 anos fizeram-se representar na proporção nada desprezível de 4,5\%. A presença de sororreagentes nas idades entre 1 e 4 anos, isto é, nascidos entre 1972 e 1977, revela ter ocorrido transmissão da infecção chagásica nessa área, embora não se possa descartar a possibilidade de contribuição da via congênita. Nesse particular, o inquérito demonstrou positividade sorológica de $15,9 \%$ na maior parte do grupo das mulheres em idade fértil, de 15 a 49 anos, tornando-se necessária uma avaliação de riscos 
para estabelecer seu papel na produção de casos observados em anos subsequentes ${ }^{1}$. Inserido próximo à microrregião Campos de Itapetininga situa-se o município de Taquarituba que, por apresentar, ainda no início dos anos 70, populações de triatomíneos vetores intradomiciliares, foi incluído em pesquisa sobre avaliação soroepidemiológica da infecção chagásica em amostra da população humana, entre os anos de 1974 e 1976. Os resultados publicados para este município sugeriram a eficácia das atividades de controle lá realizadas ${ }^{23}$.

A situação descrita anteriormente contrasta vivamente com aquela observada na microrregião homogênea Encosta Ocidental da Mantiqueira Paulista, na Região de Campinas. Nesta, já em 1970, estava sob controle T. infestans, o principal vetor do Estado e surgia um novo desafio: a ocorrência de P. megistus, considerado vetor secundário, encontrado em habitações humanas, seus anexos e terrenos circunjacentes, infectado por T. cruzi, com ingesta reagente para sangue humano e de animais reservatórios, principalmente Didelphis azarae e Rattus rattus, também infectados ${ }^{24,25,26}$.

Quanto à sororreatividade, a Microrregião Encosta Ocidental da Mantiqueira Paulista apresentou níveis bem distintos: variação de $0 \%$ a 11,6\%, sendo sua média, 3\%, quase um terço da observada em Campos de Itapetininga.

Quanto às idades dos sororreagentes, obteve-se média de 48,6 anos, correspondente aos nascidos no ano de 1932. Dos 10 casos sororreagentes, após nova colheita de amostra, observaram-se em 9 deles, títulos situados no limiar de sensibilidade da técnica, isto é, iguais a 20, sendo assim considerados como duvidosos. Apenas em um caso o título, anteriormente 40 , passou a 160 . Alterações em títulos já considerados baixos, como os observados em diluição de corte, para negativos ou então reagentes apenas para uma diluição menor, não são infrequentes em inquéritos sorológicos e tampouco desmerecem o trabalho realizado ${ }^{27}$. Em 8 casos houve o encontro de outros sororreagentes na casa; em duas delas, irmãos da mesma faixa etária. Os familiares de apenas 2 casos não eram sororreagentes. A presença de mãe sororreagente foi observada em 6 casos, razão suficiente para incluir-se a formulação de hipótese de infecção congênita, merecedora de investigação mais minuciosa. Aliás, faltaram informações sobre: naturalidade; tempo de permanência dos atuais habitantes em cada localidade; história da movimentação dos casos; presença de triatomíneos vetores nas casas, em diferentes oportunidades. Essas lacunas constituem lamentável falha nesse tipo de inquérito, impedindo a classificação de casos como autóctones e importados. Dados apresentados para dois municípios dessa microrregião, Caconde e São José do Rio Pardo, de resultados de entrevista realizada entre sororreagentes, concluem que $66,1 \%$ e $22,9 \%$ dos casos, respectivamente, classificavam-se como autóctones dos municípios e 33,9\% e 77,1\% como importados de outros municípios de São Paulo e de outros estados da Federação ${ }^{28}$. As prevalências de autoctonia e de importados para Caconde foram calculadas como sendo, ainda, em 4,1\% e 4,8\% e para São José do Rio Pardo, 0,5\% e 3,2\%, respectivamente. Tais diferenças, justificadas por condições sociais mais favoráveis em Caconde, para essa maior transmissão pretérita ${ }^{28}$, relacionam-se ao menor desenvolvimento de capital, nesse município, em épocas em que T. infestans era o principal vetor.
Dos 12 municípios que compõem a microrregião, Caconde foi o que apresentou o maior percentual de sororreatividade, contribuindo com $32 \%$ de todos os reagentes verificados, seguido por Mococa, com 20,6\%. A curva de distribuição dos sororreagentes, por grupo etário, demonstra que o quadro da infecção assumiu maior importância, na população amostrada, por volta dos anos 20-30, observando-se o pico de sororreatividade nas idades entre 50 e 59 anos. A curva sobe gradualmente até as idades 20-29 anos, sem ultrapassar a unidade e, entre 30 e 49 anos, sofre um incremento, para atingir o ápice nas idades 50-59 anos; declinando discretamente nas idades maiores. Entretanto, mesmo sem conhecer dados que permitam correlação dos resultados sorológicos e naturalidade da população da área, pela importância da economia cafeeira de muitos de seus municípios ${ }^{19}$, supõe-se que a microrregião Encosta Ocidental da Mantiqueira Paulista teve o apogeu da transmissão pelo menos 30 anos antes da microrregião Campos de Itapetininga. É possível que migrantes do Estado de Minas Gerais também fossem uma parcela do contingente de sororreagentes verificado na região.

Excetuando Águas da Prata e Caconde, não há registros antigos para outros municípios da Encosta Ocidental da Mantiqueira Paulista com sororreagentes ${ }^{29}$. Estes se relacionam apenas aos casos comprovadamente autóctones dos municípios mencionados. Já os dados entomológicos demonstravam a presença, em 1941, de T. infestans em onze deles, excluindo-se apenas Águas da Prata, onde havia relato de P. megistus ${ }^{30}$. Em 1951, T. infestans é relatado em todos eles e P. megistus é descrito em Mococa, São José do Rio Pardo e Vargem Grande do Sul ${ }^{31}$. Nos dados correspondentes a levantamentos sorológicos, realizados entre os anos de 1951 a 1957, está registrada sororreatividade, sem os percentuais, em Caconde, Divinolândia (então pertencente a São José do Rio Pardo), Espírito Santo do Pinhal, Itobi (então Distrito de Casa Branca), Mococa, Santo Antônio do Jardim (então Distrito de Pinhal), São João da Boa Vista, São José do Rio Pardo, São Sebastião da Grama, Tapiratiba e Vargem Grande do Sul. Águas da Prata figura como tendo reações negativas de Guerreiro \& Machado $^{21}$. Para o ano 1951, reações positivas em crianças do município de Pinhal são relatadas ${ }^{32}$. Essa microrregião fazia parte da área endêmica ${ }^{6}$, responsável pela maior parte da produção cafeeira do estado, em fins do século XIX ${ }^{17,19}$.

A caracterização das duas áreas, quanto aos títulos dos sororreagentes, não diferiu significativamente, sendo típica de área de baixa endemicidade ${ }^{15}$, apenas distinguindo-se Campos de Itapetininga por frequências um pouco mais elevadas. As médias geométricas dos títulos dos reagentes, 100 em Campos de Itapetininga e 165 na Encosta Ocidental da Mantiqueira Paulista não chegam a diferir o equivalente a um intervalo entre diluições de soro. De qualquer modo, os resultados dos exames da população de Campos de Itapetininga denotam a obtenção do controle em épocas mais recentes do que na área de Campinas: o ângulo observado na curva de distribuição de sororreatividade por grupos etários é maior em Campos de Itapetininga do que na Encosta, até atingir o pico nas idades de 20 a 29 anos. Apenas nos grupos etários acima de 50 anos, é que as curvas são similares. Um dos efeitos das alterações da distribuição dos sororreagentes é a redução dos riscos de transmissão congênita na área da Encosta, em parte devido ao fato de a média de idade dos sororreagentes ser mais elevada. 
Após a nova estratégia de uso de sorologia, adotada no PCDCh, a partir de 1984, e até o ano de 1997, a atividade foi mantida nos municípios da microrregião Campos de Itapetininga devido às notificações de triatomíneos vetores e como decorrência de trabalhos de rotina lá realizados. Em Itaporanga (até 1993) e Riversul (até 1994), houve o encontro de triatomíneos vetores em domicílios humanos; entretanto, não foram assinaladas pessoas sororreagentes com idades inferiores a 15 anos. Barão de Antonina esteve presente até 1988; Angatuba, Buri, Guareí e Itapeva, até 1994; Itapetininga, até 1995 e Itararé, até 1997. Dos 10 municípios, apenas Itapetininga não apresentou sororreagentes no período. As colheitas de sangue estiveram vinculadas ao encontro de T. infestans em Angatuba, em 1984 e 1985, em Itaberá, em 1986, 1987 e 1988 e em Itapetininga, em 1985, bem como de P. megistus, que nos demais municípios foi a espécie prevalente. Quanto aos resultados da sorologia, 4 de 5 casos registrados com idades inferiores a 15 anos foram detectados nessa microrregião: um deles foi repetido após dois anos, em Itararé, 1985 e 1987, ocasião em que exames de seus familiares revelaram outros sororreagentes. Em Guareí, também um caso se mostrou relacionado com sororreagentes da mesma família. Obviamente, a atualização de dados referentes aos municípios está sujeita a erros decorrentes da diminuição da amostra examinada, posto que o encontro de infectados chagásicos torna-se cada vez menos frequente, após o controle da transmissão. Importa esclarecer que, em locais de expressivo passado chagásico, as condições favoráveis à transmissão tornaram-se eventos raros. Para determinação da prevalência atual, da infecção chagásica, seria necessária a colheita de amostras mais abrangentes. É esperado que o controle da transmissão da doença de Chagas implique a redução do número de sororreagentes dos grupos etários menores, uma vez que não se espera cura espontânea dos já infectados. Os sororreagentes, antes de desaparecerem por óbito, deverão ser encontrados em grupos etários cada vez mais elevados ${ }^{1}$.

Considerando-se a totalidade dos municípios da Encosta Ocidental da Mantiqueira Paulista, observa-se pequena redução da sororreatividade entre 1980 e os anos que se seguiram: de $3 \%$ para $2,4 \%$, segundo avaliações ulteriores. Caconde, Mococa, São José do Rio Pardo e São Sebastião da Grama apresentaram condições de desencadeamento de sorologia até 1997; Águas da Prata, até 1989; Divinolândia, Tapiratiba e Vargem Grande do Sul, até 1994; Espírito Santo do Pinhal e Santo Antônio do Jardim, até 1995 e São João da Boa Vista, até 1996. É neste último município que, em 1994, ocorreu um caso reagente de criança de 12 anos de idade, no limiar estabelecido para positividade (título = 32) sem, entretanto, colher-se nova amostra para confirmação de resultado; exames de outros moradores da mesma casa resultaram negativos ${ }^{1}$.

Quanto à presença de vetores, P. megistus foi predominante em todos os municípios; em Itobi, Mococa, São João da Boa Vista, São José do Rio Pardo e Vargem Grande do Sul também foi identificada a ocorrência de R. neglectus. Em Espírito Santo do Pinhal, além desta espécie, foi encontrado Triatoma arthurneivai Lent e Martins, 1940. Em São Sebastião da Grama, P. megistus e T. arthurneivai e, em Tapiratiba, em 1984, T. infestans com ingesta com reação positiva para sangue humano, não foi associado a casos humanos sororreagentes ${ }^{1}$.
Nesta área, como em outras sob controle da transmissão vetorial, é essencial o rigor da vigilância epidemiológica, como o demonstram os trabalhos iniciados pela SUCEN na década de $1970^{4,25,26}$, incluindo a pesquisa em animais domésticos e sinantrópicos, afora o estímulo e pronto atendimento às denúncias efetuadas por moradores. Apenas é questionável o uso da sorologia aplicada na ocasião em que há suspeita de transmissão recente, por ser sobejamente conhecido que o método sorológico, isoladamente, não é apropriado para diagnosticar caso recente de infecção ${ }^{33,34}$, embora se tenha conseguido demonstrar reações fortemente positivas em testes Chagas látex de casos agudos aparentes e inaparentes em São Felipe, Bahia ${ }^{35}$. À suspeita de infecção recente, os métodos de visualização de formas sangüíneas diretos e indiretos, são soberanos ${ }^{36,37}$. Para evitar-se a ocorrência de falsos negativos, possível nesses casos, o valor da sorologia estará na comprovação de soroconversão.

A Região de Campinas permaneceu objeto de estudos soroepidemiológicos em alguns de seus municípios, pela presença de $P$. megistus, dedicando especial atenção à microrregião Encosta Ocidental da Mantiqueira Paulista ${ }^{38}$. 0 Serviço Regional manteve inalterada a programação prevista, em detrimento de outras áreas que sofreram as pressões do controle de Aedes e respondeu por $62 \%$ das amostras colhidas no estado no período de 1984 a $1997^{1}$. De maneira exemplar, manteve um fluxo de encaminhamento de infectados chagásicos detectados no PCDCh, principalmente originários dos municípios da Encosta, ao Grupo de Estudos em Doença de Chagas (GEDOCH) da Faculdade de Medicina da UNICAMP, em Campinas ${ }^{39,40,41}$.

\section{AGRADECIMENTOS}

Alair Perini Fucks, Vera Lúcia Pereira Chiaccola e Antônio Marcos de Aparecida Levy, do Setor de Xenodiagnóstico do Instituto "Dante Pazzanese" de Cardiologia, da Secretaria de EstadodaSaúdede SãoPaulo que, àépocadarealizaçãodos exames sorológicos, cederam soros-controles de pacientes chagásicos.

\section{REFERÊNCIAS}

1. Carvalho ME. Sorologia da infecção chagásica no Programa de Controle do Estado de São Paulo, Brasil [Tese de doutorado]. São Paulo: Faculdade de Saúde Pública da USP; 2000.

2. Buralli GM. Estudo do controle dos triatomíneos domiciliados no Estado de São Paulo [Dissertação de mestrado]. São Paulo: Faculdade de Saúde Pública da USP; 1985.

3. Rocha e Silva EO, Guarita OF, Ishihata GK. Doença de Chagas: atividades de controle dos transmissores no Estado de São Paulo; Brasil. Rev Bras Malariol D Trop 1979; 31:99-119.

4. Rocha e Silva EO, Wanderley DMV, Rodrigues VLCC. Triatoma infestans importância, controle e eliminação da espécie no Estado de São Paulo, Brasil. Rev Soc Bras Med Trop 1998; 31: 73-88.

5. Guarita OF, Fomm AS, Brigido RM, Pimenta Filho TT. Inquérito sorológico para avaliação da infecção chagásica do grupo etário de 9 a 14 anos dos escolares do Estado de São Paulo, Brasil. São Paulo: Secretaria de Estado da Saúde de São Paulo - SUCEN; 1978.

6. Silva LJ. Evolução da doença de Chagas no Estado de São Paulo. [Tese de doutorado] - Ribeirão Preto, SP; Faculdade de Medicina de Ribeirão Preto da USP; 1981. 
7. Paschoal L. Borrador sobre a distribuição de triatomíneos nos municípios do Estado de São Paulo, de 1950 a 1980. São Paulo: Superintendência de Controle de Endemias (SUCEN). 1980; mimeo.

8. Carvalho ME, Ferreira CS. Soroepidemiologia da infecção chagásica: contribuição para o aumento do rendimento da reação de imunofluorescência indireta. Cad Saude Publica 1985; 1: 478-481.

9. Camargo ME. Fluorescent antibody test for the serodiagnosis of American Trypanosomiasis. Technical modification employing preserved culture forms of Trypanosoma cruzi in a slide test. Rev Inst Med Trop S Paulo 1966; 8:227-234.

10. Ferreira CS, Carvalho ME. Reações de imunofluorescência indireta: algumas simplificações de sua técnica. Rev Saude Publ 1973; 7:303-306.

11. Ferreira CS, Carvalho ME. Padronização de uso de papel-filtro como suporte de material para reações sorológicas. Rev Bras Malariol D Trop1982; 34:82-86.

12. Camargo ME, Amato Neto V. Anti-T. cruzi antibodies as serologic evidence of recent infection. Rev Inst Med Trop S Paulo 1974; 16:200-202.

13. Diamond GA. Clinical epistemology of sensitivity and specificity. J Clin Epidemiol 992; 45:9-13.

14. Sadun EH, Duxbury RE, Williams JS, Anderson RI. Fluorescent antibody test for the serodiagnosis of African and American trypanosomiasis in man. J Parasitol 1963; 49:385-388.

15. Kagan IG. Parasitic diseases. In: Paul JR, White C, editors. Serological epidemiology. New York: Academic Press; 1973. p. 155-167.

16. Dawson-Saunders B, Trapp RG. Basic \& clinical biostatistics. $2^{\text {nd }}$ ed. Norwalk, Connecticut: Appleton \& Lange; 1994.

17. Litvoc J, Oya DRT, Goldbaum M, Maluf J, França JBM, Salvo A. Plano de amostragem na estimativa da prevalência de infecção chagásica. In: Anais do 15ํㅡㄹ Congresso da Sociedade Brasileira de Medicina Tropical; 1979.

18. Fundação SEADE. O novo retrato de São Paulo. Avaliação dos primeiros resultados do censo demográfico de 1991. $2^{\mathrm{a}}$ ed. São Paulo; 1993.

19. Fundação IBGE. Enciclopédia dos municípios brasileiros. Rio de Janeiro; 1958. v. XXVIII-XXX.

20. Unti O, Silva TL. Levantamento da moléstia de Chagas no Estado de São Paulo pela reação sorológica. Arq Hig Saúde Pública 1952; 17:123-132.

21. Coda D, Falci N, Mendes FAT. Contribuição para o estudo e a profilaxia da moléstia de Chagas no Estado de São Paulo. Rev Inst Adolfo Lutz 1958; 18:83-121.

22. Silva LJ. Desbravamento, agricultura e doença: a doença de Chagas no Estado de São Paulo. Cad Saúde Públ 1986; 2:124-140.

23. Carvalho ME, Latorre MRDO, Ferreira CS, Mello CS, Barata JMS. Soroprevalência de infecção chagásica em área de Triatoma infestans após medidas de controle. Rev Saude Publ 2000; 34:15-20.

24. Forattini OP, Rocha e Silva EO, Rabello EX, Andrade JCR, Rodrigues VLCC. Aspectos ecológicos da tripanossomíase americana. XIII - Potencial enzoótico doméstico em área de P. megistus, sob vigilância epidemiológica. Rev Saude Publ 1978; 12:417-424.

25. Rocha e Silva EO, Andrade JCR, Lima AR. Importância dos animais sinantrópicos no controle da endemia chagásica. Rev Saude Publ 1975; 9:371-381
26. Rocha e Silva EO, Andrade JCR, Rodrigues VLCC. Investigação de foco, uma das atividades das campanhas de controle dos transmissores da tripanossomíase americana. Rev Saude Publ 1978; 12:425-431.

27. Dias JCP. Perspectivas para o controle da doença de Chagas humana em áreas endêmicas através de profilaxia domiciliar com inseticidas de ação residual. Experiência de Bambuí, Minas Gerais, Brasil. [Monografia de conclusão de mestrado]. Belo Horizonte: Faculdade de Medicina da UFMG; 1974.

28. Litvoc J. Doença de Chagas e estrutura social: infestação domiciliar e infecção humana em áreas submetidas a ações de controle [Tese de doutorado]. São Paulo: Faculdade de Medicina da USP; 1985.

29. Freitas JLP. Dados atuais sobre a distribuição de triatomídeos e moléstia de Chagas no Estado de São Paulo. Rev Paul Med 1950; 37:227-236.

30. Rosenfeld G, Cardoso FA. Distribuição dos triatomídeos e da moléstia de Chagas no Estado de São Paulo (Brasil). Rev Clin S Paulo 1941; 9:198-209.

31. Lima FO, Silva TL. Distribuição dos triatomíneos no Estado de São Paulo. Arq Hig Saude Publica 1952; 17:27-55.

32. Unti O, Silva TL, Aguiar AA. Alguns dados sobre a reação de Machado \& Guerreiro na infância. Arq Hig Saude Publica 1952; 51:529-534.

33. Luquetti AO. Diagnóstico laboratorial da doença de Chagas. Rev Soc Bras Med Trop 1992; 25: 22-23.

34. Schattschneider ER, Lopes ER, Alencar JE de, Bienzle U, Feldmeier H A comparative study of four serological methods of acute and chronic Chagas' disease in Brazilian patients. Trop Geogr Med 1992; 44:210-218.

35. Teixeira MGLC. Doença de Chagas: estudo da forma aguda inaparente. [Dissertação de mestrado] Rio de Janeiro: Faculdade de Medicina da UFRJ; 1977.

36. Chuit R, Subias E, Perez AC, Paulone I, Wisnivesky-Colli C, Segura EL. Usefulness of serology for the evaluation of Trypanosoma cruzi transmission in endemic areas of Chagas' disease. Rev Soc Bras Med Trop 1989; 22:119-124.

37. Freitas JLP. Contribuição para o estudo do diagnóstico da moléstia de Chagas por processos de laboratório[Tese de doutorado]. São Paulo: Faculdade de Medicina da USP; 1947.

38. Lima VLC, Yaguchi MK, Alves ZCPVT. Aspectos da atividade de "notificação de barbeiros" pela população no controle de Panstrongylus megistus em 12 municípios da região noroeste do Estado de São Paulo, Brasil, 1974 a 1983. Rev Saude Publ 1990; 24:497-505.

39. Secretaria de Estado da Saúde de São Paulo. Superintendência de Controle de Endemias (SUCEN). Departamento de Combate a Vetores (DCV). Planejamentos do Serviço Regional de Campinas 1985-1988. Campinas (SP): SUCEN/DCV; 1985-1988.

40. Secretaria de Estado da Saúde de São Paulo. Superintendência de Controle de Endemias (SUCEN). Departamento de Combate a Vetores (DCV). Planejamentos do Serviço Regional de Campinas 1990. Campinas (SP): SUCEN/DCV; 1989.

41. Secretaria de Estado da Saúde de São Paulo. Superintendência de Controle de Endemias (SUCEN). Descentralização de atividades de controle de endemias. São Paulo, SUCEN; 1994. 